\title{
Geochemical variability in the soils of Bangladesh as affected by sources of irrigation water and inundation land types
}

\author{
M. Tanvir A. Chowdhury, ${ }^{1,2}$. Andrew A. Meharg ${ }^{3} \cdot$ Adam H. Price $^{2} \cdot$ Gareth J. Norton $^{2}$
}

Received: 19 September 2020 / Accepted: 21 January 2021 / Published online: 2 February 2021

(c) The Author(s) 2021 OPEN

\begin{abstract}
Paddy soils in Bangladesh experience extensive irrigation with groundwater and surface water, both having variable geochemical constituents. The soils also have topological variations across the landscape. To understand the geochemical variability in the soils as affected by the different sources of irrigation water and the topographical variability, cultivation zones of paddy soils irrigated with both groundwater $(n=904)$ and surface water $(n=281)$ across Bangladesh were sampled and analyzed for a suit of seventeen geochemical elements. This study also assessed the extent and distribution of arsenic and the other geochemical elements in the paddy soils $(n=1209)$ as well as in a set of neighboring non-paddy soils $(n=235)$ within the different inundation land types (highland, medium highland-1, medium highland-2, medium lowland, lowland and very lowland) of Bangladesh. The mean concentrations of aluminum (26,000 mg/kg), cobalt (13 mg/ $\mathrm{kg})$, copper (32 mg/kg), iron (28,250 mg/kg), lead (18 mg/kg), magnesium ( $8050 \mathrm{mg} / \mathrm{kg})$, molybdenum $(1.02 \mathrm{mg} / \mathrm{kg})$, nickel $(41 \mathrm{mg} / \mathrm{kg})$, potassium $(4870 \mathrm{mg} / \mathrm{kg})$, sodium $(750 \mathrm{mg} / \mathrm{kg}$ ) and zinc $(70 \mathrm{mg} / \mathrm{kg})$ in the surface water-irrigated paddy soils were found to be significantly $(0.001 \geq p \leq 0.05)$ higher compared to the concentrations in the soils irrigated with groundwater $(23,400 ; 12 ; 28 ; 25,650 ; 17 ; 7000 ; 0.96 ; 36 ; 4350 ; 600 ;$ and $62 \mathrm{mg} / \mathrm{kg}$, respectively). Therefore, surface water used for paddy irrigation could increase the inputs of a number of toxic elements in the paddy soils having potential risk of crop contamination. Arsenic in the paddy and non-paddy soils varied significantly $(F=24.74, p<0.001$ and $F=3.42$, $p<0.01$, respectively) within the inundation land types, the very lowland (9.95 and $6.72 \mathrm{mg} / \mathrm{kg}$, respectively) and lowland ( 8.33 and $5.20 \mathrm{mg} / \mathrm{kg}$, respectively) having the highest mean arsenic concentrations and the medium highland-1 (5.27 and $5.17 \mathrm{mg} / \mathrm{kg}$, respectively) having the lowest. The concentrations of the other geochemical elements analyzed were also observed to be higher, in general, in the soils of very lowland and lowland. Since the low-level lands are predominantly used for paddy cultivation, higher concentrations of various toxic elements, particularly arsenic, in such soils pose an increased risk of rice toxicity in Bangladesh. The results of this study present an inimitable geochemical database for the surface soils across Bangladesh which can be used in any future studies on the geomorphologically variable agricultural and non-agricultural Bangladeshi soils, providing a basis for environmental pollution assessment and sustainable mitigation approaches.
\end{abstract}

Keywords Arsenic · Heavy metal · Paddy soil · Irrigation water $\cdot$ Inundation land types

Supplementary Information The online version contains supplementary material available at https://doi.org/10.1007/s42452-021-04269 $-1$.

M. Tanvir A. Chowdhury, mta.chowdhury@du.ac.bd | 'Department of Soil, Water and Environment, University of Dhaka, Dhaka 1000, Bangladesh. ${ }^{2}$ Institute of Biological and Environmental Sciences, University of Aberdeen, Cruickshank Building, St. Machar Drive, Aberdeen AB24 3UU, UK. ${ }^{3}$ School of Biological Sciences, Queen's University Belfast, 19 Chlorine Gardens, Belfast, Northern Ireland BT9 5DL, UK. 


\section{Introduction}

Agriculture is a top priority sector in Bangladesh playing a vital role in the economic growth of the country [1]. Bangladesh ranks 4 th in the world in terms of rice production, rice consumption and area under rice production [2]. Over 70 percent of the country's land area is currently under agricultural practices, of which 75 percent is under rice cultivation $[2,3]$. About 40 percent of the net cultivable area is under irrigation and 60 percent of the total irrigation requirement is met by the groundwater, which in many places has elevated concentrations of arsenic [4]. The extensive use of the arsenic contaminated groundwater for paddy irrigation, particularly in the dry season, is potentially increasing arsenic load in the soils [4-7]. Thus, arsenic contamination of agricultural soils has become a major environmental problem in Bangladesh [8]. Despite the groundwater input of arsenic in the paddy field soils, other geochemical elements like, aluminum, calcium, iron, lead, magnesium, manganese, molybdenum, nickel, phosphorus, potassium, sodium and zinc are also added to the soils through groundwater irrigation, although the magnitude and spatial distribution patterns are variable $[9,10]$. Different mobilization processes in the aquifer sediments have been reported to induce different concentrations of elements in the groundwater of alluvial floodplains in Bangladesh and elsewhere $[11,12]$.

Along with the groundwater, surface water is also used for paddy irrigation in many areas of Bangladesh where abundant $[8,13]$. Although the baseline concentrations of arsenic in surface water have been reported to be low, for example, river water contains arsenic in the range of $0.1-2 \mu \mathrm{g} / \mathrm{l}$ which is three orders of magnitude lower than arsenic rich groundwater [14], the surface water in Bangladesh is at risk of contamination with a variety of toxic heavy metals [4, 15-17]. Elevated levels of toxic elements in surface water can come from a range of sources, such as from the discharge of untreated or partially treated effluents from industries, indiscriminate use of toxic metal containing fertilizers and pesticides in agricultural lands and other anthropogenic activities $[4,16,18,19]$. Thus, surface water can contribute to the inputs of toxic heavy metals into the irrigated paddies. This ultimately warrants further concern with respect to the toxic metal contamination of the agricultural lands followed by accumulation into crops. These can potentially affect the national food security as well as can pose a threat to the human health in Bangladesh. However, total metal concentrations in agricultural soils also reflect the soil's geological origin and mineral weathering besides the inputs from anthropogenic activities [12, 20-22].

\section{SN Applied Sciences}

The soils of Bangladesh are naturally variable in their geochemical fingerprints [7]. Bangladesh has a complex geological and geomorphological setting with an active sedimentary depositional history [8, 9]. Bangladesh has three major geomorphological units-hill, terrace and floodplain areas $[4,23]$. The hills and the uplifted terraces are of Pleistocene age and the floodplains are of Holocene age. To understand and characterize the landforms and landscapes of the geomorphological areas, Bangladesh is divided into 20 main physiographic regions based on the parent material in which individual soil types were formed and the landscape on which the soils were developed [24]. These physiographical units are also characterized by land topography and age of the land formation through sediment deposition over time [23]. In Bangladesh, the topographic levels of land in relation to the normal depth and duration of seasonal flooding, known as the inundation/ depth-of-flooding land types, have been classified into highland (above flood level), medium highland-1 (normal flooding depth is up to $30 \mathrm{~cm}$ ), medium highland-2 (normal flooding depth is $30-90 \mathrm{~cm}$ ), medium lowland (normal flooding depth is $90-180 \mathrm{~cm}$ ), lowland (normal flooding depth is $180-300 \mathrm{~cm}$ ), very lowland (normal flooding depth is over $300 \mathrm{~cm}$ ) and bottomland (depression sites which remain wet throughout the year) [24]. The diversity and complexity of soils in Bangladesh are influenced by variations in the flooding depth within the different inundation land types $[25,26]$.

The variability of arsenic in the paddy soils of Bangladesh is inherently high $[7,27,28]$. The dynamics of arsenic in soil vary due to variations in indigenous soil properties, particularly the ionic constituents of iron, manganese, aluminum, calcium, magnesium, phosphate, sulfate and carbonate, and $\mathrm{pH}$, redox potential and texture of soil as well as the microbially mediated biogeochemical interactions that control the biogeochemical cycling of arsenic in soils [7, 29-34]. Temporal variability and spatial heterogeneity (both lateral and vertical) in the distribution of arsenic in the paddy soils have also been reported [35, 36]. Arsenic concentration in the topsoil increases during the irrigation period and remobilizes and decreases over the monsoon season particularly in the deeply flooded soils through monsoon flooding and the floodwater flows into rivers [35, 37-39]. However, as the paddy soils have, in general, a higher arsenic concentration compared to the adjacent non-paddy soils, the process of loss of arsenic from the soils by monsoonal floods is not sufficient to reduce the arsenic concentration in the paddy soils back to the non-paddy soil background concentration [7]. Thus, the accumulation and release of arsenic in soils vary within the toposequence of a landscape due to variations in relief. There is very limited data available to compare 
the differences in arsenic concentrations at or within all the inundation land types in Bangladesh.

Enrichment and variabilities of a range of geochemical elements have been found in the geomorphologically different soils of Bangladesh, which may perhaps be explained by the differences in sedimentary depositional environments acting across the landscape of the country [7]. The changes in the river courses over time altered the regional sediment depositional patterns. It also reformed the regional topological features, drainage conditions as well as soil types [8]. The complex river systems in the country actively rework the sediment deposition and mobilization patterns that give rise to the variability in the indigenous soils [40-42]. The newer sediments redeposit onto the less- or un-weathered older sediments as well as they also become mixed together. Thus, it alters the exposed surface soil sediments through lensing of the sediments redeposited and remobilized that may cause the variability in the soil sediments [43]. The complex interactions between soil properties, climate, agricultural management practices and land topographic variations in the paddy soil environment in Bangladesh can also enhance such variability in the inherent soil geochemical relationships [44].

In the present study, we examined the extent and distribution of arsenic and a range of other geochemical elements within the different inundation land types across Bangladesh as well as the extent and distribution of the geochemical elements in paddy soils irrigated with groundwater and surface water. Cultivation zones of paddy soils irrigated with both groundwater $(n=904)$ and surface water $(n=281)$ across Bangladesh, from latitude $22^{\circ} 06^{\prime}$ to $24^{\circ} 53^{\prime}$ and longitude $88^{\circ} 20^{\prime}$ to $90^{\circ} 59^{\prime}$ were sampled and analyzed for arsenic and a suite of 16 other elements: aluminum, calcium, cadmium, cobalt, chromium, copper, iron, lead, magnesium, manganese, molybdenum, nickel, phosphorus, potassium, sodium and zinc. The paddy soils along with a subset of non-irrigated non-paddy soils $(n=235)$ were categorized according to the 6 inundation land types of Bangladesh: highland, medium highland-1, medium highland-2, medium lowland, lowland and very lowland. The data were used to determine whether the sources of irrigation water impact on the concentrations of the geochemical elements in paddy soils, and to assess the spatial heterogeneity of the geochemical constituents in the soils, both paddy and non-paddy, within the inundation land types. By examining the concentrations of arsenic and other geochemical elements in the soils, we aimed to understand the impacts that paddy irrigation water and inundation land types have on soil elemental concentrations at a landscape scale. This study presents, so far, the largest geochemical database of Bangladeshi soils. It needs to be noted that the data presented here were previously published in Chowdhury et al. [7], where the data were presented and discussed in relation to arsenic and the different physiographic regions of Bangladesh rather than inundation land types as here. While topology of the landscape is an important factor particularly considering the geochemical variability in an active sedimentary depositional environment like in Bangladesh, this further analysis adds additional insight into the elemental distribution in agricultural and non-agricultural soils as affected by the topographical variations across the landscape of the country.

\section{Materials and methods}

\subsection{Collection of soil samples}

A total of 1444 soil samples (topsoil, $0-15 \mathrm{~cm}$ from the surface) from paddy fields $(n=1209)$ and neighboring nonpaddy areas $(n=235)$ were collected from 57 sub-districts (upazilas) of 17 districts within the Holocene floodplains and Pleistocene terraces of Bangladesh as described in Chowdhury et al. [7]. Non-paddy soils were defined as the soils where paddy cultivation and groundwater irrigation had not been practiced within known memory of the farmers. The source of irrigation water for the paddy soils was recorded (groundwater, $n=904$; surface water, $n=281$; both, $n=24$ ). Only the soils that had a non-mixed irrigation source were used for analyzing the impact of irrigation type on soil geochemistry.

The collected soils were categorized into six inundation land types of Bangladesh [24], using the inundation landtype map sourced from Bangladesh Agricultural Research Council (BARC): highland, HL ( $n=258$ paddy and 57 nonpaddy soils); medium highland-1, MHL-1 ( $n=62$ paddy and 10 non-paddy soils); medium highland-2, MHL-2 ( $n=226$ paddy and 55 non-paddy soils); medium lowland, MLL ( $n=230$ paddy and 37 non-paddy soils); lowland, LL ( $n=394$ paddy and 69 non-paddy soils); and very lowland, VLL ( $n=39$ paddy and 7 non-paddy soils) (Fig. S1).

\subsection{Sample processing and chemical analysis}

The samples used in this study had previously been analyzed for total arsenic and a set of other geochemical elements. Sample preparation and processing can be found in Chowdhury et al. [7]. The ICP-MS (Agilent Technologies $7500 \mathrm{c}$, Japan) was used to determine the total concentrations of arsenic, cadmium, cobalt, copper, chromium, lead, manganese, molybdenum, nickel, phosphorus and zinc in the soil digests and the MPAES (Agilent Technologies 4100 Series, USA) was used to determine the total concentrations of aluminum, calcium, iron, magnesium, potassium 

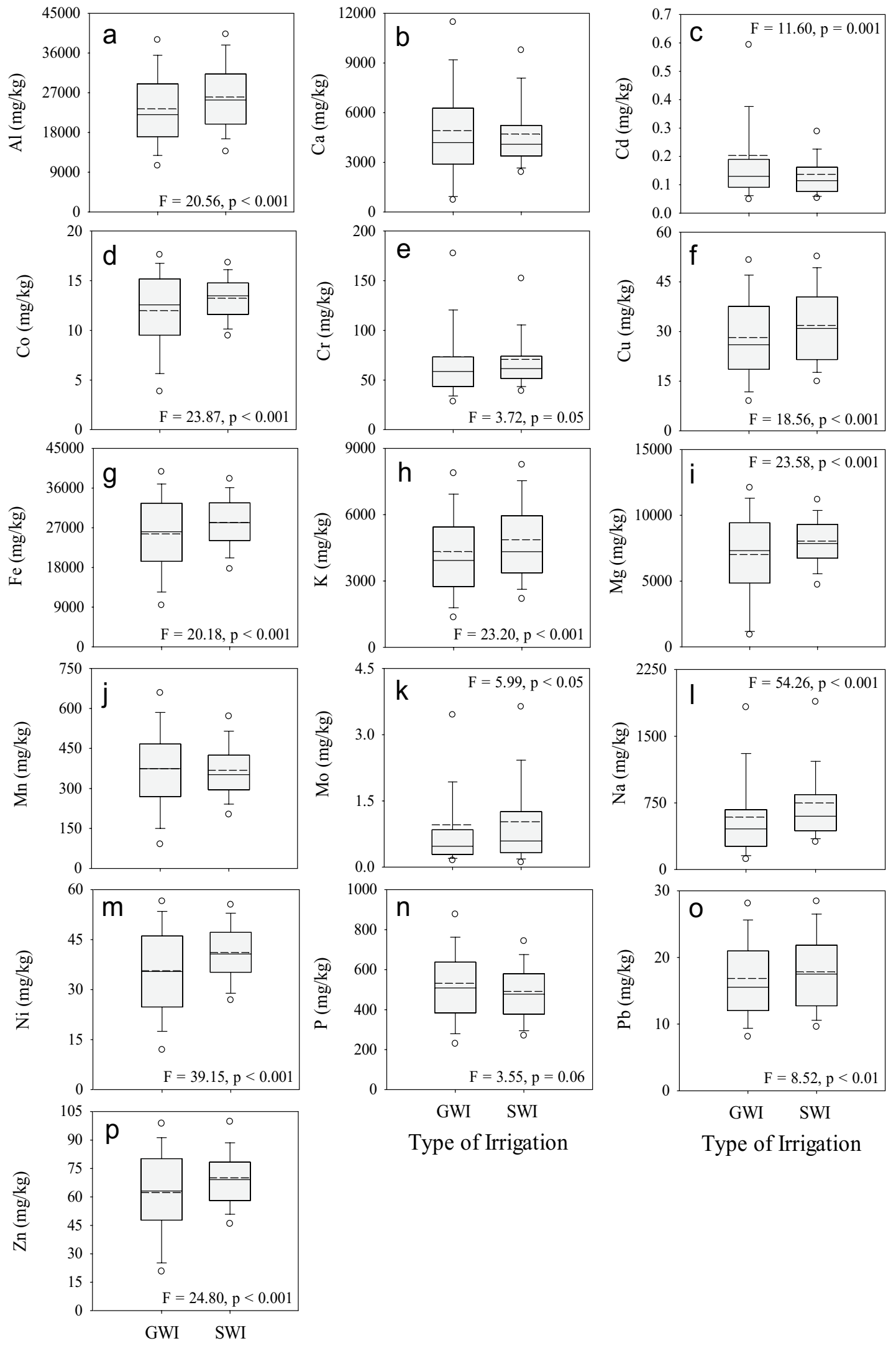

Type of Irrigation

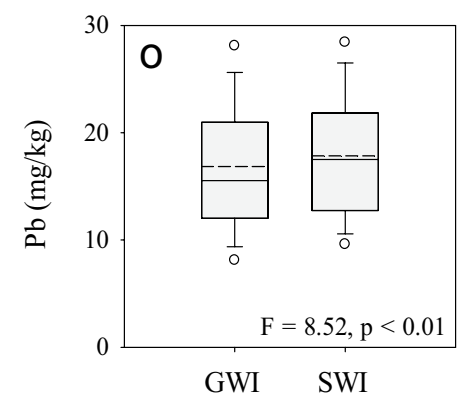

Type of Irrigation

Type of Irrigation 
4Fig. 1 Box and whisker plots showing the concentrations of different elements in paddy soils irrigated with groundwater and surface water. $\mathrm{GWI}=$ groundwater irrigation, $n=904$ and $\mathrm{SWI}=$ surface water irrigation, $n=281$. The boxplots indicate the lower and upper quartile (box), the median (solid line), the mean (dash line), the 10th and 90th percentiles (whiskers) and the 5th and 95th percentiles (circles). The $F$-value and $p$ value are from one-way analysis of variance (ANOVA) test

and sodium in the soil digests. In each batch of digestion, $10 \%$ of the total number of samples were selected randomly for duplicate analysis $(n=172)$. Every batch of samples consisted of 33 randomly selected soil samples, 4 duplicates, 1 blank and 1 soil CRM (certified reference material) (NCS ZC 73007, China National Analysis Center for Iron and Steel), which were randomized prior to chemical analysis.

\subsection{Statistical analysis}

All statistical analyses were performed using the statistical software Minitab v.19 (State College PA) and SigmaPlot v.14 (Systat Software Inc., CA). The data were checked for normality and were transformed prior to statistical analysis where appropriate.

\section{Results and discussion}

\subsection{Extent and variability of the geochemical elements in paddy soils irrigated with groundwater and surface water}

The concentrations of the elements in the paddy and non-paddy soils analyzed are presented in Table S1. The individual soil maps showing the geographical distribution of the element concentrations in the non-paddy and paddy soils are presented in Figs. S2-S33. Compared to the soils irrigated with groundwater, the surface water-irrigated paddy soils had higher concentrations of aluminum, cobalt, copper, iron, potassium, magnesium, molybdenum, sodium, nickel, lead and zinc (Fig. 1). On the other hand, the groundwater-irrigated paddy soils were found to have higher concentrations of cadmium, chromium and manganese compared to the elements in the surface water-irrigated soils (Fig. 1). These elemental concentrations indicated that paddy soils in Bangladesh contained high levels of a number of heavy metals, exceeding the typical concentrations of the elements in soils $[45,46]$ as well as the concentrations reported for some agricultural soils of Bangladesh in previous studies [47-49]. The concentrations of the elements, except calcium, manganese and phosphorus, in the paddy soils irrigated with groundwater varied significantly $(0.001 \geq p \leq 0.05)$ from the concentrations of the elements in the soils irrigated with surface waters (Fig. 1). Calcium (in the form of gypsum, $\mathrm{CaSO}_{4} \cdot 2 \mathrm{H}_{2} \mathrm{O}$ ) and phosphorus (mainly as triple super phosphate, TSP) fertilizers are applied to the agricultural soils and the elements are amply present in both groundwater and surface water [10]. A wide range of manganese concentrations were found both in the groundwaterand surface water-irrigated soils, a number of soils $(21 \%$, $n=188$ and $13 \%, n=37$ of the groundwater- and surface water-irrigated soils, respectively;) having concentrations exceeding the world-soil average concentration of $488 \mathrm{mg} / \mathrm{kg}$ [46]. High manganese concentrations (up to $618 \mathrm{mg} / \mathrm{kg}$ ) in some agricultural soils of Bangladesh have previously been reported [48, 49]. High concentrations of manganese in the groundwater of Bangladesh have also been reported in BGS and DPHE [9] and Hasan and Ali [50] indicating geogenic abundance of manganese in Bangladesh sedimentary environment.

While the average concentrations of cadmium in uncontaminated soils are less than $1 \mathrm{mg} / \mathrm{kg}$ [46], the concentrations of cadmium were as high as $5.58 \mathrm{mg} / \mathrm{kg}$ in the paddy soils, which indicated a potential concern from the view point of national health and food security in Bangladesh. Meharg et al. [51] reported that cadmium concentrations in rice grain were the highest in Bangladesh among twelve different countries across the world, exposing Bangladeshi populations to excessively high levels of cadmium in their diet. The use of contaminated water for irrigation, discharge of effluents and wastewater in the surrounding land areas, and long-term use of cadmium containing phosphatic fertilizers in the agricultural lands could be the possible reasons for the high concentrations of cadmium accumulated in these soils $[4,17,52-55]$. High concentrations of sodium were mostly found in the soils of coastal districts, where paddy irrigation was usually done with sodium laden brackish water. Elevated concentration of sodium in soil solution affects various morphological, physiological and biochemical functions in plants and limits the uptake of mineral nutrient elements by the plant roots, thus causing reduced yield as well as poor nutritional quality of the crops [56-59].

Chowdhury et al. [7] previously reported that arsenic concentrations in the paddy soils irrigated with groundwater were significantly different compared to the soils irrigated with surface water across Bangladesh, the average arsenic concentrations being higher in the groundwater-irrigated soils $(8.5 \mathrm{mg} / \mathrm{kg})$ than in the soils irrigated with surface water $(5.7 \mathrm{mg} / \mathrm{kg})$. The study explained that the differences in soil arsenic due to different irrigation waters appeared to be a general trend across the country, and the arsenic concentrations in the paddy soils might be confounded by the underlying geomorphological variabilities. The groundwater used for irrigation might also be 
an important source for the inputs of some elements like aluminum, calcium, iron, lead, magnesium, manganese, molybdenum, nickel, phosphorus, potassium, sodium and zinc in the paddy soils. However, differences in geochemical mobilizations in the groundwater sediments and surface soils that are largely regulated by complex interactions of geological and pedoenvironmental factors lead to variable inputs of the elements in the groundwater-soil systems $[11,12,34,44,60]$. The elevated concentrations of the elements, particularly the heavy metals, in the surface water-irrigated topsoil could also reflect the impacts of anthropogenic activities $[4,17,54]$. It is probable that the sources of surface water become contaminated to some extent as a result of contamination through discharge of untreated or partially treated effluents from nearby industries and small factories, indiscriminate use of toxic metal containing fertilizers and pesticides in agricultural fields, application of untreated sewage sludge in arable lands and vehicular emissions from the roads and highways alongside the agricultural lands $[4,17,18,54,61]$. While irrigation with groundwater increases soil arsenic concentrations, the use of surface water, which is generally free of or very low in arsenic, is recommended for paddy irrigation $[13,62,63]$. The present study revealed that irrigating paddy soils with surface water could reduce arsenic loading in the paddy soils, but at the same time increase the concentrations of some other toxic elements in the soils.

\subsection{Geochemical variations in the soils within the inundation land types}

Variabilities of a range of non-essential (aluminum, arsenic, cadmium, cobalt, chromium, sodium and lead) and essential (macronutrients: calcium, magnesium, potassium and phosphorous; and micronutrients: copper, iron, manganese, molybdenum, nickel and zinc) elements in the soils of different inundation land types were assessed in the present study. The non-essential/toxic and essential/macro- and micronutrient elements were found to be varied highly significantly in the paddy and non-paddy soils of the inundation land types (Figs. 2, 3, 4 and Figs. S34-S36, respectively). However, less variations were observed in the non-paddy soil elemental concentrations compared to the variations in the paddy soils within the different inundation land types. Soil $\mathrm{pH}$ also varied significantly $\left({ }^{\mathrm{ANOVA}} F=13.58, p<0.001\right.$ and ${ }^{\mathrm{ANOVA}} F=3.57, p<0.01$ for paddy and non-paddy soils, respectively) within the inundation land types.

The average arsenic concentration was found to be the highest in the very lowland paddy soils $(10 \mathrm{mg} / \mathrm{kg}$ ) among the inundation land types. The average arsenic concentrations in the paddy soils at different inundation land types were observed in the order of very lowland $>$ lowland $>$ medium highland $-2>$ medium lowland $>$ highland $>$ medium highland- 1 (Fig. 2B). The concentrations of the other geochemical elements analyzed were also observed to be higher, in general, in the soils of very lowland and lowland (Figs. 2, 3, 4). Higher concentrations of chromium (93.47 and $93.28 \mathrm{mg} / \mathrm{kg}$, respectively), copper ( 35.16 and $33.10 \mathrm{mg} / \mathrm{kg}$, respectively), lead (19.04 and $18.89 \mathrm{mg} / \mathrm{kg}$, respectively) and nickel (44.13 and 42.89, respectively) were observed in the paddy soils of very lowland and lowland compared to the high lands (Figs. 2E, 4A, $2 \mathrm{G}, 4 \mathrm{E}$, respectively). Higher concentrations of cobalt in paddy soils were found in lowland and medium lowland (13.66 and $13.26 \mathrm{mg} / \mathrm{kg}$, respectively) (Fig. 2D). The average concentrations of all the elements, except cadmium, in the paddy soils were found to be the maximum in very lowland and/or in lowland, and the minimum in medium highland-1. The average concentration of cadmium in the paddy soils was found to be the highest in medium highland-2 $(0.24 \mathrm{mg} / \mathrm{kg})$, followed by highland $(0.21 \mathrm{mg} / \mathrm{kg})$, medium lowland $(0.20 \mathrm{mg} / \mathrm{kg})$, lowland $(0.15 \mathrm{mg} / \mathrm{kg})$, very lowland $(0.14 \mathrm{mg} / \mathrm{kg})$ and medium highland $-1(0.13 \mathrm{mg} /$ $\mathrm{kg}$ ) (Fig. 2C). The average cadmium concentration in nonpaddy soils was also found to be the highest in medium highland-2 $(0.19 \mathrm{mg} / \mathrm{kg})$. In the non-paddy soils, the average concentrations of most of the elements were observed to be the highest in very lowland or medium highland-2, and the lowest in highland or medium highland-1. Surprisingly, concentrations of all the elements in the paddy soils, and only calcium, cadmium and phosphorus in the non-paddy soils were found to be the lowest in medium highland-1. The reason is perhaps related to the complex landscape topographical variations within the local areas [8].

Bangladeshi soils are highly and inherently variable in their concentrations of geochemical elements [7]. Spatial occurrence and accumulation of elements as well as their mobility and availability in soils are largely regulated by the topography of the landscape $[12,64]$. The distribution of arsenic in Bangladeshi paddy soils is heterogeneous, the variability being temporal and spatial, both lateral and vertical $[27,28,35,36]$. It is well documented that arsenic accumulation in the topsoil of paddy fields occurs due to the use of arsenic rich groundwater for irrigation purpose $[6,7]$. Arsenic in the surface paddy soils that increases during the dry season irrigation period decreases over the monsoon season through monsoon flooding [35, 37, 39]. Due to the natural relief of the lands, the monsoon floodwater stands on the lowlands for prolonged time. It remobilizes and redistributes soil arsenic, which was deposited at the time of irrigation in the preceding dry season, laterally over a large area. At the end of the monsoon season, this arsenic containing floodwater is transported to the local rivers, and ultimately to the Bay of Bengal leaving 
Fig. 2 Box and whisker plots showing the concentrations of non-essential elements in paddy soils at the different inundation land types: $\mathrm{HL}$, Highland; MHL-1, Medium highland-1; MHL-2, Medium highland-2; MLL, Medium lowland; LL, Lowland; and VLL, Very lowland. The numbers of samples $(n)$ at each of the inundation land types are given within the parentheses. The boxplots indicate the lower and upper quartile (box), the median (solid line), the 10th and 90th percentiles (whiskers) and the 5th and 95th percentiles (circles). One-way analysis of variance was used to compare pair-wise the means of the elements at each of the inundation land types. Land types that share the same letter $\mathbf{a}-\mathbf{d}$ are not significantly different. The letters indicate Tukey groupings for the inundation land types with respect to their mean soil elemental concentrations
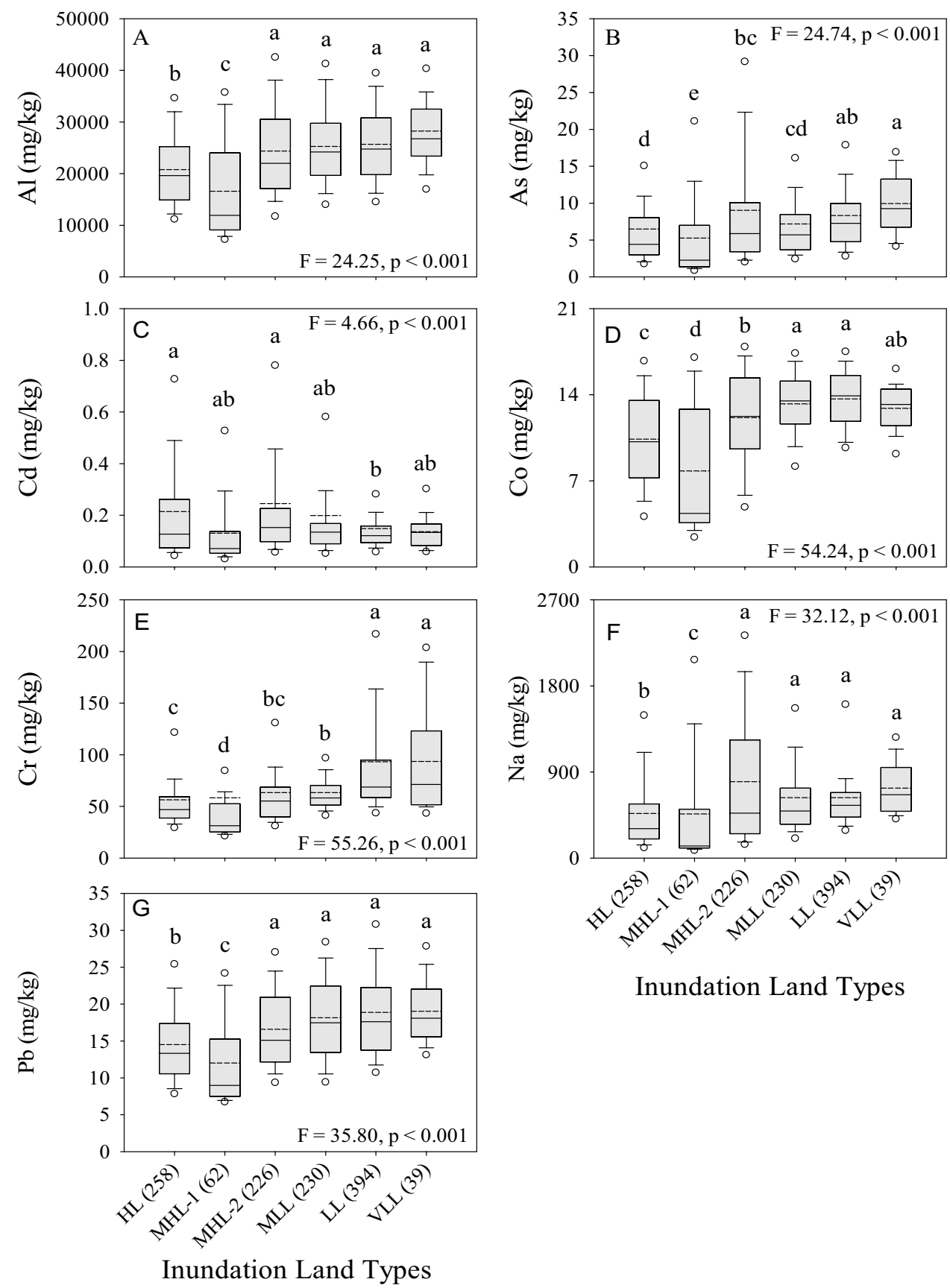

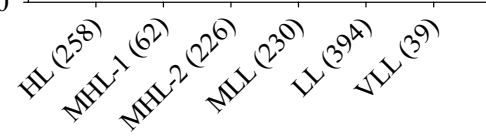

Inundation Land Types behind only a residual amount of arsenic on the paddies $[39,65]$. The river water carrying arsenic may cause further deposition and redistribution in the downstream landscape [39]. On the other hand, in the areas, for instance, highlands where monsoon flooding is limited, the arsenic added during the irrigation season has been found to be retained into the soil [65]. Thus, the inundation land types affect the distribution and retention of arsenic in the paddies $[26,66]$. However, arsenic in paddy soils added through irrigation water can also be lost through vertical leaching to sub-surfaces [67-69]. Loss of arsenic from the paddies can also occur through biovolatilization, although thought to be on smaller scale [70]. The overall management of the paddy soils make the retention and removal of arsenic in the soils complex [7]. The irrigation season in Bangladesh is normally from December until May, and the majority of the present soil samples were collected during February-March [37]. A part of the soil samples was also collected just before the onset of the monsoon season (during June-July), where the monsoon season usually lingers from mid-June to late October [37]. The concentrations of arsenic found in the present soils, therefore, were 

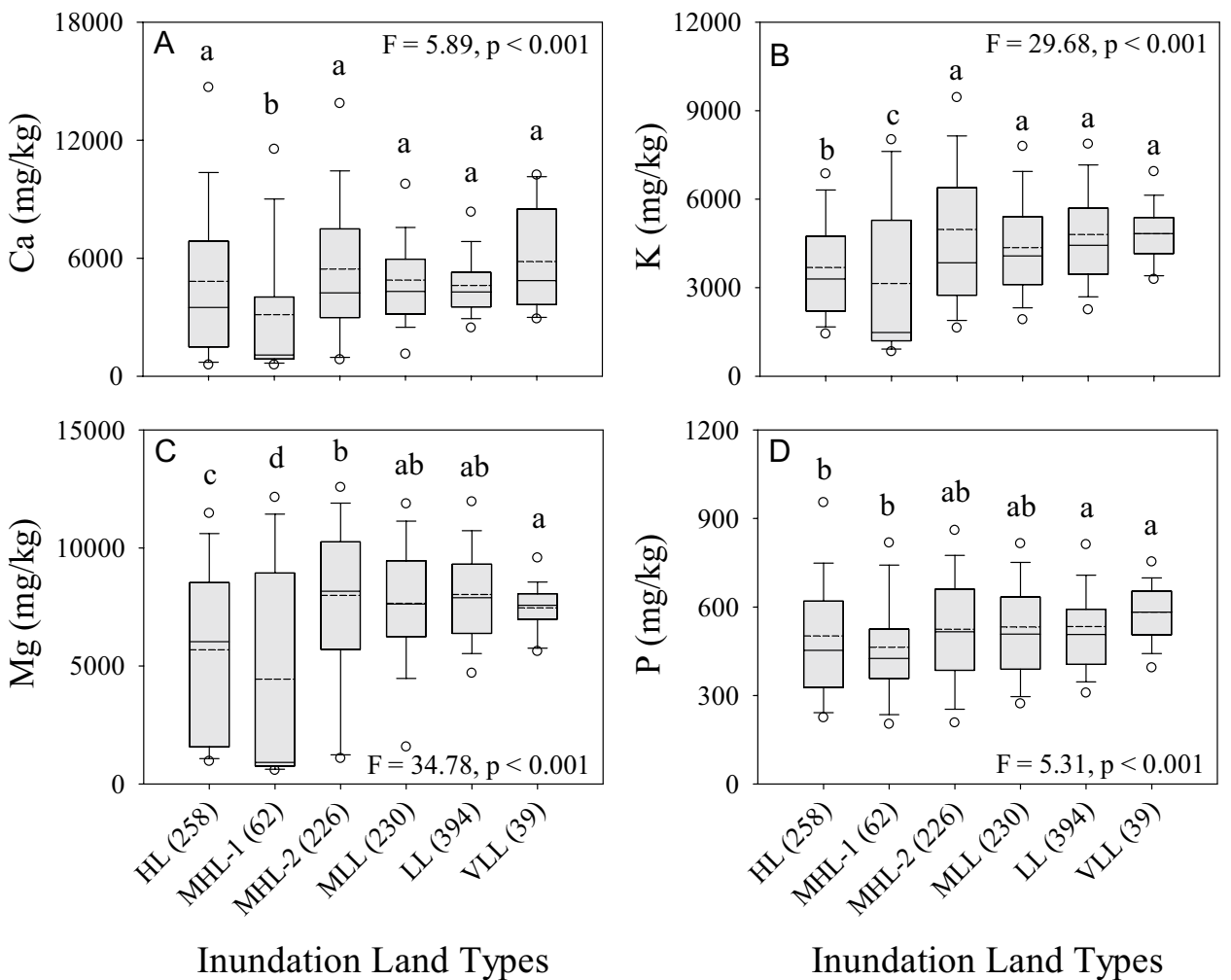

Fig. 3 Box and whisker plots showing the concentrations of macronutrient elements in paddy soils at the different inundation land types: HL, Highland; MHL-1, Medium highland-1; MHL-2, Medium highland-2; MLL, Medium lowland; LL, Lowland; and VLL, Very lowland. The numbers of samples $(n)$ at each of the inundation land types are given within the parentheses. The boxplots indicate the lower and upper quartile (box), the median (solid line), the 10th

a combination of the native soil arsenic and any arsenic added through irrigation in that season, plus the residual arsenic remaining after the previous monsoon flooding.

Higher concentrations of arsenic as well as other geochemical elements in the low-level lands during the irrigation season suggest that the elements were laterally transported to the bottom end fields through surface run-off of the irrigation water as well as through movement of soil particles down the gradient during the growing season of the rice crop. It is also probable that soil arsenic in the low-level lands was not reduced greatly by flooding in the prior monsoon season [66]. The arsenic and other elements added in those low-lying areas were perhaps retained in the topsoil followed by transport down the gradient, although a part of the elements could be lost through other mechanisms already mentioned earlier. Elevated accumulation of the elements in the soils of the low-level lands could also be due to their association with fine-grain sediments and organic matter present in the low-lying flooded/ depression soils $[26,62,64]$. The elevated accumulations in the lower lands of some elements

and 90th percentiles (whiskers) and the 5th and 95th percentiles (circles). One-way analysis of variance was used to compare pairwise the means of the elements at each of the inundation land types. Land types that share the same letter $\mathbf{a}-\mathbf{d}$ are not significantly different. The letters indicate Tukey groupings for the inundation land types with respect to their mean soil elemental concentrations

highly toxic to plants such as aluminum, arsenic, cadmium, cobalt, chromium, copper and lead poses a substantial risk to the rice cultivation, which is extensively done in those low-level lands across Bangladesh. Moreover, although the essential nutrient elements were elevated in the low-level lands, high concentrations of arsenic and heavy metals in the soils can limit the accumulation of nutrient elements into rice grains [71, 72]. Both these situations have the potential to lead to rice grains with higher toxic elements and lower nutrient concentrations. However, this is not well investigated and warrants further study in Bangladesh to understand the grain versus soil associations at the different inundation land types for toxic heavy metals as well as primary mineral nutrients of human health importance.

\section{Conclusion}

Higher concentrations of a range of heavy metals, such as aluminum, cobalt, copper, iron, molybdenum, nickel, lead and zinc were found in the surface water-irrigated 
Fig. 4 Box and whisker plots showing the concentrations of micronutrient elements in paddy soils at the different inundation land types: $\mathrm{HL}$, Highland; MHL-1, Medium highland-1; MHL-2, Medium highland-2; MLL, Medium lowland; LL, Lowland; and VLL, Very lowland. The numbers of samples $(n)$ at each of the inundation land types are given within the parentheses. The boxplots indicate the lower and upper quartile (box), the median (solid line), the 10th and 90th percentiles (whiskers), and the 5th and 95th percentiles (circles). One-way analysis of variance was used to compare pair-wise the means of the elements at each of the inundation land types. Land types that share the same letter $\mathbf{a}-\mathbf{d}$ are not significantly different. The letters indicate Tukey groupings for the inundation land types with respect to their mean soil elemental concentrations
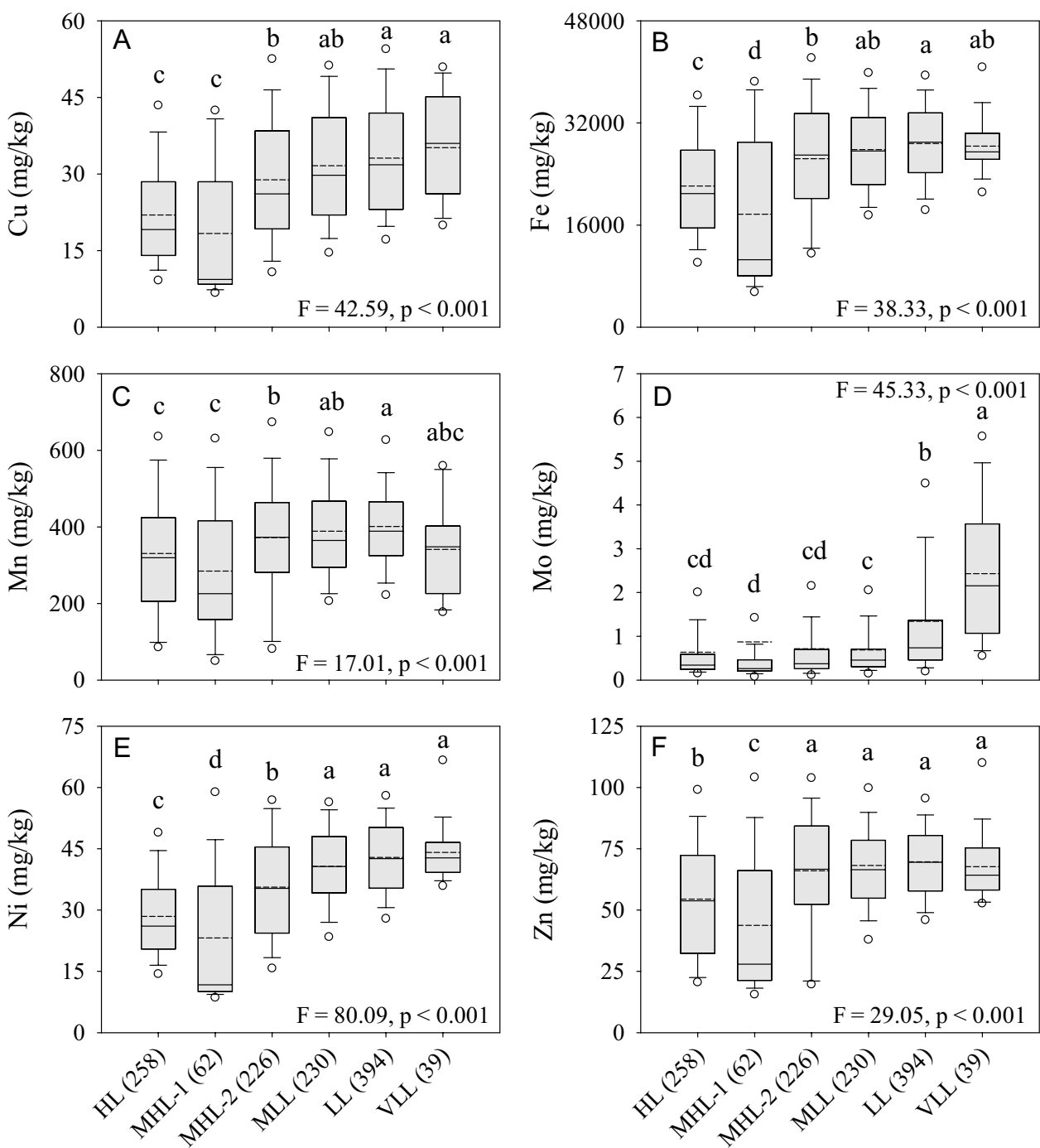

Inundation Land Types

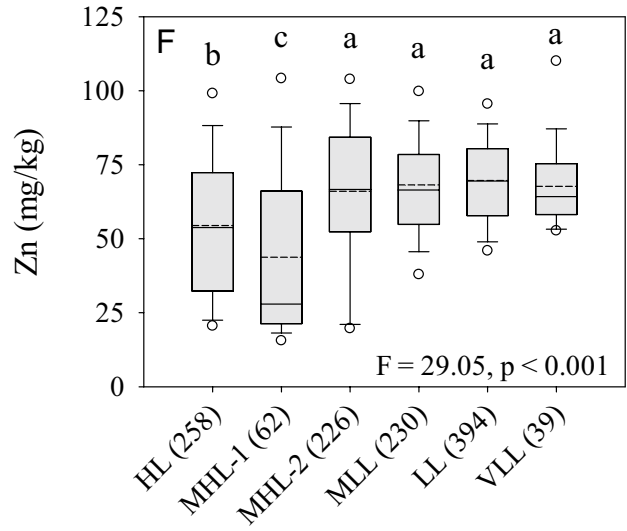

Inundation Land Types paddy soils compared to the soils irrigated with groundwater. This indicates inputs of toxic metals in the soils due to paddy irrigation with surface water, which could lead to contamination of the food chain and pose potential risk to human health. The presence of elevated concentrations of cadmium in the irrigated paddy soils also indicates a concern considering its possible accumulation in food crops. Variabilities in the concentrations of different non-essential/toxic and essential nutrient elements were found in the paddy and adjacent nonpaddy soils of different inundation land types of Bangladesh, with greater variations observed in the paddy soils. The average arsenic concentrations in the paddy soils at different inundation land types were observed in the order of very lowland $>$ lowland $>$ medium highland-2 $>$ medium lowland $>$ highland $>$ medium highland-1. Elevated accumulations of a range of toxic metal elements, such as aluminum, chromium, cobalt, copper, lead and nickel in the paddy soils of very lowland and lowland areas, compared to the highlands, present substantial risks considering that rice, the staple food in Bangladesh, is extensively cultivated in these low lands. Further studies and periodic monitoring are needed to assess the extent of soil and crop contamination with toxic elements induced through surface water irrigation practices across Bangladesh. Further fine-scale soil investigations are also vital to explore the extent of contamination of the lowland soils at a landscape scale as well as to relate this to the yield and nutritional quality of the growing crops. The results of this study present an inimitable geochemical database for the surface soils across Bangladesh which can be used in any future studies on the geomorphologically variable agricultural and non-agricultural Bangladeshi soils, providing a basis for environmental pollution assessment and sustainable mitigation approaches. 
Acknowledgements This work was done as part of a doctoral fellowship plan funded by the Commonwealth Scholarship Commission in the UK. We gratefully acknowledge Bangladesh-Australia Centre for Environmental Research and Department of Soil, Water and Environment of the University of Dhaka for the support during the processing and preparation of the soil samples in Bangladesh. We also gratefully acknowledge the Computer and GIS Unit of Bangladesh Agricultural Research Council (BARC) for providing GIS files for mapping of soils and land types. The soil samples were imported into the UK under import license IMP/SOIL/6/2013 issued by Science and Advice for Scottish Agriculture.

Author contributions MTAC collected samples, prepared materials, analyzed and interpreted the data and wrote the first draft of the manuscript. AAM contributed to the study conception and commented on previous versions of the manuscript. AHP and GJN contributed to the study conception and design, supervised the study and commented on previous versions of the manuscript. All authors read and approved the final manuscript.

Funding This study was funded by the Commonwealth Scholarship Commission in the UK.

Availability of data and material The datasets used and/or analyzed during the current study are available from the corresponding author on reasonable request.

\section{Compliance with ethical standards}

Conflict of interest The authors declare that they have no conflict of interest.

Consent for publication All the authors have given their consent for publication of this manuscript.

Open Access This article is licensed under a Creative Commons Attribution 4.0 International License, which permits use, sharing, adaptation, distribution and reproduction in any medium or format, as long as you give appropriate credit to the original author(s) and the source, provide a link to the Creative Commons licence, and indicate if changes were made. The images or other third party material in this article are included in the article's Creative Commons licence, unless indicated otherwise in a credit line to the material. If material is not included in the article's Creative Commons licence and your intended use is not permitted by statutory regulation or exceeds the permitted use, you will need to obtain permission directly from the copyright holder. To view a copy of this licence, visit http://creativecommons .org/licenses/by/4.0/.

\section{References}

1. BBS (Bangladesh Bureau of Statistics) (2018) 45 years Agriculture Statistics of Major Crops (Aus, Amon, Boro, Jute, Potato and Wheat). Statistics and Informatics Division (SID), Bangladesh Bureau of Statistics (BBS), Ministry of Planning, Government of the People's Republic of Bangladesh. http://www.bbs.gov.bd/ site/page/453af260-6aea-4331-b4a5-7b66fe63ba61/. Accessed 09 Dec 2020

2. IRRI (International Rice Research Institute) (2020) Rice profile in Bangladesh. http://books.irri.org/Bangladesh_IRRI_brochure. pdf. Accessed 09 Dec 2020
3. FAO (Food and Agriculture Organization) (2018) Bangladesh country profile. http://faostat.fao.org/static/syb/syb_16.pdf. Accessed 09 Dec 2020

4. Huq SMI, Shoaib JUM (2013) The soils of Bangladesh. World soils book series. Springer, Dordrecht

5. Meharg AA, Rahman M (2003) Arsenic contamination of Bangladesh paddy field soils: implications for rice contribution to arsenic consumption. Environ Sci Technol 37(2):229-234. https ://doi.org/10.1021/es0259842

6. Huq SMI, Rahman A, Sultana N, Naidu R (2003) Extent and severity of arsenic contamination in soils of Bangladesh. In: Ahmed MF, Ali MA, Adeel Z (eds) Fate of arsenic in the environment. ITN Centre, Bangladesh University of Engineering and Technology, Dhaka, pp 69-84

7. Chowdhury MTA, Deacon CM, Jones GD, Huq SMI, Williams PN, Hoque AFMM, Winkel LHE, Price AH, Norton GJ, Meharg AA (2017) Arsenic in Bangladeshi soils related to physiographic region, paddy management, and mirco- and macro-elemental status. Sci Total Environ 590-591:406-415. https://doi. org/10.1016/j.scitotenv.2016.11.191

8. Brammer H (2012) The physical geography of Bangladesh. The University Press Ltd., Dhaka

9. BGS (British Geological Survey), DPHE (Department of Public Health Engineering) (2001) Arsenic contamination of groundwater in Bangladesh. In: Kinniburg DG, Smedley PL (eds) Volume 2: Final report, British Geological Survey report, WC/00/19. British Geological Survey, Keyworth

10. BBS (Bangladesh Bureau of Statistics), UNICEF (United Nations International Children's Emergency Fund) (2011) Bangladesh national drinking water quality survey of 2009. https://washd ata.org/sites/default/files/documents/reports/2019-06/Bangl adesh-2009-MICS-water-quality-report.pdf. Accessed 18 Dec 2020

11. Ravenscroft P, MCArthur JM, Hoque BA (2001) Geochemical and palaeohydrologicical controls on pollution of groundwater by arsenic. In: Chappell WR, Abernathy CO, Calderon R (eds) Arsenic exposure, health effects IV. Elsevier Science Ltd., Oxford, pp $53-78$

12. Kanellopoulos C, Argyraki A, Mitropoulos P (2015) Geochemistry of serpentine agricultural soil and associated groundwater chemistry and vegetation in the area of Atalanti, Greece. J Geochem Explor 158:22-33. https://doi.org/10.1016/j.gexpl o.2015.06.013

13. Williams PN, Islam MR, Adomako EE, Raab A, Hossain SA, Zhu Y-G, Feldmann J, Meharg AA (2006) Increase in rice grain arsenic for regions of Bangladesh irrigating paddies with elevated arsenic in groundwaters. Environ Sci Technol 40:4903-4908. https:// doi.org/10.1021/es060222i

14. Smedley PL, Kinniburgh DG (2002) A review of the source, behaviour and distribution of arsenic in natural waters. Appl Geochem 17:517-568. https://doi.org/10.1016/S0883 -2927(02)00018-5

15. Chowdhury MTA, Nesa L, Kashem MA, Huq SMI (2010) Assessment of the phytoavailability of $\mathrm{Cd}, \mathrm{Pb}$ and $\mathrm{Zn}$ using various extraction procedures. Pedologist 53(3):80-95. https://doi. org/10.18920/pedologist.53.3_80

16. Islam MS, Ahmed MK, Raknuzzaman M, Habibullah-Al-Mamun M, Islam MK (2015) Heavy metal pollution in surface water and sediment: a preliminary assessment of an urban river in a developing country. Ecol Indic 48:282-291. https://doi.org/10.1016/j. ecolind.2014.08.016

17. Islam MA, Romić D, Akber MA, Romić M (2018) Trace metals accumulation in soil irrigated with polluted water and assessment of human health risk from vegetable consumption in Bangladesh. Environ Geochem Health 40(1):59-85. https://doi. org/10.1007/s10653-017-9907-8 
18. Ahmed MK, Ahamed S, Rahman S, Haque MR, Islam MM (2009) Heavy metals concentration in water, sediments and their bioaccumulations in some freshwater fishes and mussel in Dhaleshwari River. Bangladesh Terr Aquat Environ Toxicol 3(1):33-41

19. Chowdhury MTA, Nesa L, Huq SMI (2015) Assessment of the phytoavailability of $\mathrm{Cu}$ and $\mathrm{Ni}$ using various extraction procedures. Dhaka Univ J Biol Sci 24(1):1-16

20. Kersten M, Förstner U (1989) Speciation of trace elements in sediments. In: Batley GE (ed) Trace element speciation: analytical methods and problems. CRC, Boca Raton, pp 245-317

21. Kanellopoulos C, Argyraki A (2013) Soil baseline geochemistry and plant response in areas of complex geology. Application to NW Euboea, Greece. Chemie der Erde Geochem 73(4):519-532. https://doi.org/10.1016/j.chemer.2013.06.006

22. Kanellopoulos C (2020) Influence of ultramafic rocks and hot springs with travertine depositions on geochemical composition and baseline of soils. Application to eastern central Greece. Geoderma. https://doi.org/10.1016/j.geoderma.2020.114649

23. Brammer $\mathrm{H}$ (1996) The geography of the soils of Bangladesh. The University Press Ltd., Dhaka

24. FAO (Food and Agriculture Organization), UNDP (United Nations Development Programme) (1988) Land resources appraisal of Bangladesh for agricultural development. Report 2: Agroecological Regions of Bangladesh. Report prepared for the Government of the People's Republic of Bangladesh by the Food and Agriculture Organization of United Nations, United Nations Development Programme, BGD/81/035, Technical report 2, 1988

25. Brammer H (1999) Floods in Bangladesh: geographical background to the 1987 and 1988 floods. Geogr J 156:12-22

26. Huq SMI, Hoque AFMM, Joardar JC, Shoaib JU (2008) Arsenic movement in the profiles of some Bangladesh soils. Can J Pure Appl Sci 2:251-259

27. Garnier J-M, Garnier J, Jézéquel D, Angeletti B (2015) Using DET and DGT probes (ferrihydrite and titanium dioxide) to investigate arsenic concentrations in soil porewater of an arseniccontaminated paddy field in Bangladesh. Sci Total Environ 536:306-315. https://doi.org/10.1016/j.scitotenv.2015.07.065

28. Chowdhury MTA, Deacon CM, Steel E, Huq SMI, Paton GI, Price AH, Williams PN, Meharg AA, Norton GJ (2018) Physiographical variability in arsenic dynamics in Bangladeshi soils. Sci Total Environ 612:1365-1372. https://doi.org/10.1016/j.scito tenv.2017.09.030

29. Bissen M, Frimmel FH (2003) Arsenic - a review. Part I: occurrence, toxicity, speciation, mobility. Acta Hydrochim Hydrobiol 31(1):9-18. https://doi.org/10.1002/aheh.200390025

30. Mahimairaja S, Bolan NS, Adriano DC, Robinson B (2005) Arsenic contamination and its risk management in complex environmental settings. Adv Agron 86:1-82. https://doi.org/10.1016/ S0065-2113(05)86001-8

31. Nriagu JO, Bhattacharya P, Mukherjee AB, Bundschuh J, Zevenhoven R, Loeppert RH (2007) Arsenic in soil and groundwater: an overview. In: Bhattacharya P, Mukherjee AB, Bundschuh J, Zevenhoven R, Loeppert RH (eds) Trace metals and other contaminants in the environment, vol 9. Elsevier, Oxford, pp 3-60

32. Moreno-Jiménez $E$, Esteban E, Peñalosa JM (2012) The fate of arsenic in soil-plant systems. In: Whitacre DM (ed) Reviews of environmental contamination and toxicology, vol 215. Springer, New York, pp 1-37. https://doi. org/10.1007/978-1-4614-1463-6_1

33. Saha N, Bodrud-Doza M, Islam ARMT, Begum BA, Rahman MS (2020) Hydrogeochemical evolution of shallow and deeper aquifers in central Bangladesh: arsenic mobilization process and health risk implications from the potable use of groundwater. Environ Earth Sci 79:477. https://doi.org/10.1007/s12665-02009228-4
34. Gerdelidani AF, Towfighi H, Shahbazi K, Lamb DT, Choppala G, Abbasi S, Bari ASMF, Naidu R, Rahman MM (2021) Arsenic geochemistry and mineralogy as a function of particle-size in naturally arsenic-enriched soils. J Hazard Mater. https://doi. org/10.1016/j.jhazmat.2020.123931

35. Dittmar J, Voegelin A, Roberts LC, Hug SJ, Saha GC, Ali MA, Badruzzaman ABM, Kretzschmar R (2007) Spatial distribution and temporal variability of arsenic in irrigated rice fields in Bangladesh. 2. Paddy soil. Environ Sci Technol 41(17):5967-5972. https://doi.org/10.1021/es0702972

36. Hossain MB, Jahiruddin M, Panaullah GM, Loeppert RH, Islam MR, Duxbury JM (2008) Spatial variability of arsenic concentration in soils and plants, and its relationship with iron, manganese and phosphorus. Environ Poll 156(3):739-744. https://doi. org/10.1016/j.envpol.2008.06.015

37. Dittmar J, Voegelin A, Roberts LC, Hug SJ, Saha GC, Ali MA, Badruzzaman ABM, Kretzschmar R (2010) Arsenic accumulation in a paddy field in Bangladesh: seasonal dynamics and trends over a three-year monitoring period. Environ Sci Technol 44(8):2925-2931. https://doi.org/10.1021/es903117r

38. Saha GC, Ali MA (2007) Dynamics of arsenic in agricultural soils irrigated with arsenic contaminated groundwater in Bangladesh. Sci Total Environ 379(2-3):180-189. https://doi. org/10.1016/j.scitotenv.2006.08.050

39. Roberts LC, Hug SJ, Dittmar J, Voegelin A, Kretzschmar R, Wehrli B, Cirpka OA, Saha GC, Ali MA, Badruzzaman ABM (2010) Arsenic release from paddy soils during monsoon flooding. Nat Geosci 3(1):53-59. https://doi.org/10.1038/ngeo723

40. Sullivan KA, Aller RC (1996) Diagenetic cycling of arsenic in Amazon shelf sediments. Geochim Cosmochim Acta 60:1465-1477

41. Polizzotto ML, Harvey CF, Sutton SR, Fendorf S (2005) Processes conductive to the release and transport of arsenic into aquifers of Bangladesh. Proc Natl Acad Sci 102:18819-18823

42. Guillot $S$, Garçon $M$, Weinman $B$, Gajurel A, Tisserand D, FranceLanord C, vanGeen A, Chakraborty S, Huyghe P, Upreti BN, Charlet $L$ (2015) Origin of arsenic in Late Pleistocene to Holocene sediments in the Nawalparasi district (Terai, Nepal). Environ Earth Sci 74:2571-2593. https://doi.org/10.1007/s1266 5-015-4277-y

43. Meharg AA, Scrimgeour C, Hossain SA, Fuller K, Cruickshank $K$, Williams PN, Kinniburgh DG (2006) Co-deposition of organic carbon and arsenic in Bengal Delta aquifers. Environ Sci Technol 40:4928-4935. https://doi.org/10.1021/es060722b

44. Martin M, Bonifacio E, Hossain KMJ, Huq SMI, Barberis E (2014) Arsenic fixation and mobilization in the soils of the Ganges and Meghna floodplains. Impact of pedoenvironmental properties. Geoderma 228-229:132-141. https://doi.org/10.1016/j.geode rma.2013.09.020

45. Huq SMI, Alam MD (2005) A hand book on analyses of soil, plant, and water. Bangladesh Australia Centre for Environmental Research University of Dhaka, Dhaka

46. Kabata-Pendias A (2011) Trace elements in soils and plants, 4th edn. CRC Press, Boca Raton

47. Domingo LE, Kyuma K (1983) Trace elements in tropical Asian paddy soils: I. Total trace element status. Soil Sci Plant Nutr 29(4):439-452

48. Moslehuddin AZM, Laizoo S, Egashira K (1999) Trace elements in Bangladesh paddy soils. Commun Soil Sci Plant Anal 30(13-14):1975-1996

49. Jahiruddin $M$, Harada $H$, Hatanaka T, Islam MR (2000) Status of trace elements in agricultural soils of Bangladesh and relationship with soil properties. Soil Sci Plant Nutr 46(4):963-968. https ://doi.org/10.1080/00380768.2000.10409161

50. Hasan S, Ali MA (2010) Occurrence of manganese in groundwater of Bangladesh and its implications on safe water supply. J Civ Eng 38(2):121-128 
51. Meharg AA, Norton $G$, Deacon $C$, Williams $P$, Adomako EE, Price A, Zhu Y, Li G, Zhao F-J, McGrath S, Villada A, Sommella A, De Silva PMCS, Brammer H, Dasgupta T, Islam MR (2013) Variation in rice cadmium related to human exposure. Environ Sci Technol 47:5613-5618. https://doi.org/10.1021/es400521h

52. Grant C, Sheppard S (2008) Fertilizer impacts on cadmium availability in agricultural soils and crops. Hum Ecol Risk Assess 14:210-228. https://doi.org/10.1080/10807030801934895

53. Ahmad JU, Goni MA (2010) Heavy metal contamination in water, soil, and vegetables of the industrial areas in Dhaka. Bangladesh Environ Monit Assess 166(1-4):347-357. https://doi. org/10.1007/s10661-009-1006-6

54. Miah M, Joardar J, Chowdhury S, Huq SMI, Parveen Z (2010) Contribution of diverse industrial wastes to the environmental degradation around Dhaka City. Bangladesh J Sci Res 23(1):11-16

55. Roberts TL (2014) Cadmium and phosphorous fertilizers: the issues and the science. Procedia Eng 83:52-59. https://doi. org/10.1016/j.proeng.2014.09.012

56. Grattan SR, Grieve CM (1999) Mineral nutrient acquisition and response by plants grown in saline environments. In: Pessarakli $M$ (ed) Handbook of plant and crop stress, 2nd edn. Marcel Dekker Inc., New York, pp 203-229

57. El-Bassiouny HMS, Bekheta MA (2001) Role of putrescine on growth, regulation of stomatal aperture, ionic contents and yield by two wheat cultivars under salinity stress. Egypt J Physiol Sci 2-3:235-258

58. Munns R, James RA, Läuchli A (2006) Approaches to increasing the salt tolerance of wheat and other cereals. J Exp Bot 57(5):1025-1043. https://doi.org/10.1093/jxb/erj100

59. Hussain M, Park H-W, Farooq M, Jabran K, Lee D-J (2013) Morphological and physiological basis of salt resistance in different rice genotypes. Int J Agric Biol 15(1):113-118

60. Martin M, Stanchi S, Hossain KMJ, Huq SMI, Barberis E (2015) Potential phosphorus and arsenic mobilization from Bangladesh soils by particle dispersion. Sci Total Enviro 536:973-980. https ://doi.org/10.1016/j.scitotenv.2015.06.008

61. Huq SMI, Islam NM, Das M (2000) Effect of automobile exhausts on nutritional status of soil and plant. Bangladesh J Soil Sci 26(1-2):103-111

62. Brammer H (2012) Soil complexity and arsenic mitigation. Agric Dev 17:31-35

63. Edmunds WM, Ahmed KM, Whitehead PG (2015) A review of arsenic and its impacts in groundwater of the Ganges-Brahmaputra-Meghna delta. Bangladesh Environ Sci Process Impacts 17(6):1032-1046. https://doi.org/10.1039/c4em00673a

64. Du Laing G, Rinklebe J, Vandecasteele B, Meers E, Tack FMG (2009) Trace metal behaviour in estuarine and riverine floodplain soils and sediments: a review. Sci Total Environ 407(13):39723985. https://doi.org/10.1016/j.scitotenv.2008.07.025

65. Panaullah GM, Alam T, Hossain MB, Loeppert RH, Lauren JG, Meisner CA, Ahmed ZU, Duxbury JM (2009) Arsenic toxicity to rice (Oryza sativa L.) in Bangladesh. Plant Soil 317(1-2):31-39. https://doi.org/10.1007/s11104-008-9786-y

66. Ahmed ZU, Panaullah GM, DeGloria SD, Duxbury JM (2011) Factors affecting paddy soil arsenic concentration in Bangladesh: prediction and uncertainty of geostatistical risk mapping. Sci Total Environ 412-413:324-335. https://doi.org/10.1016/j.scito tenv.2011.10.008

67. McLaren RG, Megharaj M, Naidu R (2006) Fate of arsenic in the soil environment. In: Naidu R, Smith E, Qwens G, Bhattacharya $P$, Nadebaum $P$ (eds) Managing arsenic in the environment: from soil to human health. CSIRO Publishing, Collingwood, pp 157-182

68. Khan MA, Islam MR, Panaullah GM, Duxbury JM, Jahiruddin M, Loeppert RH (2009) Fate of irrigation-water arsenic in rice soils of Bangladesh. Plant Soil 322(1):263-277. https://doi.org/10.1007/ s11104-009-9914-3

69. Heikens A, Panaullah GM, Meharg AA (2007) Arsenic behaviour from groundwater and soil to crops: impacts on agriculture and food safety. Rev Environ Contam Toxicol 189:43-87. https://doi. org/10.1007/978-0-387-35368-5_3

70. Mestrot A, Feldmann J, Krupp EM, Hossain M, Roman-Ross G, Meharg AA (2011) Field fluxes and speciation of arsines emanating from soils. Environ Sci Technol 45:1798-1804. https://doi. org/10.1021/es103463d

71. Williams $P N$, Islam $S$, Islam $R$, Jahiruddin $M$, Adomako E, Soliaman ARM, Rahman GKMM, Lu Y, Deacon C, Zhu Y-G, Meharg AA (2009) Arsenic limits trace mineral nutrition (Selenium, Zinc, and Nickel) in Bangladesh rice grain. Environ Sci Technol 43:84308436. https://doi.org/10.1021/es901825t

72. Norton GJ, Dasgupta T, Islam MR, Islam S, Zhao F-J, Stroud JL, McGrath SP, Feldmann J, Price AH, Meharg AA (2010) Arsenic influence on genetic variation in grain trace-element nutrient content in Bengal Delta grown rice. Environ Sci Technol 44:8284-8288. https://doi.org/10.1021/es101487x

Publisher's Note Springer Nature remains neutral with regard to jurisdictional claims in published maps and institutional affiliations. 